\title{
A QUESTÃO DA FORMACÃO DE \\ PROFESSORES DE EDUCAÇÃO FÍSICA E A CONCEPÇÃO DE \\ PROFESSOR ENQUANTO INTELECTUAL - REFLEXIVO - \\ TRANSFORMADOR
}

ANEGLEYCE TEODORO RODRIGUES*

RESUMO

A idéia central deste artigo é discutir a questão da formação de professores de Educação Física a partir de uma concepção de professor enquanto intelectual - reflexivo - transformador. Em primeiro lugar, tentarei discutir o atual modelo de formação docente em Educação Física e abordar a importância da prática como instrumento de análise e a reflexão do professor como alternativa ao paradigma dominante da raciona-idade técnica.

Em segundo lugar, tratarei da necessidade de se construir uma nova concepção da prática docente que eleja a dimensão reflexiva como componente fundamental da atividade do professor. E, finalmente, abordarei a questão da função social do professor como intelectual transformador no interior da escola e da universidade.

PALAVRAS-CHAVE: Formação de professores - Educação Física - Educação

\section{INTRODUÇÃO}

tualmente uma das principais problemáticas da área da Educação Física tem sido a $\mathbf{A}_{\text {formação profissional no âmbito da licenciatura. }}$

Pensar sobre o tema da formação de professores faz com que uma interrogação se torne indispensável. De que depende uma atividade docente pedagogicamente competente e politicamente comprometida com um projeto educacional de mudança?

Desde o final do curso de Educação Física venho me questionando sobre a questão da formação de professores, principalmente após a realização de uma pesquisa feita pela FEF da UFG, no ano de 1995, sobre a realidade da Educação Física escolar da rede pública de ensino em Goiânia. Este estudo procurou conhecer melhor a prática pedagógica do docente em relação às metodologias, à relação professor-aluno, aos conteúdos e à questão da formação para a cidadania. A pesquisa foi realizada em vinte escolas das redes estadual e municipal, com quarenta professores entrevistados.

Os resultados desta pesquisa demonstraram que o ensino da Educação Física escolar pública em nossa cidade está longe de uma prática comprometida com a formação para 0 exercício da cidadania. Foi possível constatar que grande parte dos entrevistados enfrenta dificuldades em relação à capacidade crítica e reflexiva sobre seu próprio papel na escola e sobre a realidade social e educacional que os cercam. A maioria dos professores desconhece as palavras básicas do repertório educacional, não se considera intelectual, desconsidera as características de classe social, ou melhor, as condições econômicas, sociais e culturais de seus alunos no momento de selecionar, aplicar e avaliar os conteúdos de ensino, entre outros problemas.

Na verdade encontramos um quadro em que os limites da prática docente dificultam uma ação mais competente e emancipadora. Tal situação, porém, não é exclusiva dos 
professores de Educação Física. Se fosse realizada a mesma pesquisa com professores das outras áreas do conhecimento escolar, possivelmente os resultados não seriam muito diferentes. Entretanto, de nada adiantaria uma crítica unilateral sobre o professor, se não forem discutidas as origens de toda esta problemática. Seria o mesmo que jogar toda a culpa sobre a vítima. A meu ver, os fatores determinantes da atuação docente estão nos cursos que formam os professores, ou seja, nas licenciaturas e nas pedagogias; nas políticas governamentais que sucateiam a escola pública e desvalorizam o professor; e no âmbito da economia e da cultura característica do modo de viver capitalista.

A idéia central deste artigo é discutir a questão da formação de professores de Educação Física a partir de uma concepção de professor, enquanto intelectual - reflexivo transformador. Em primeiro lugar, tentarei discutir o atual modelo de formação docente em Educação Física e abordar a importância da prática como instrumento de análise e reflexão do professor como alternativa ao paradigma dominante da racionalidade técnica.

Em segundo lugar, tratarei da necessidade de se construir uma nova concepção da prática docente que eleja a dimensão reflexiva como componente fundamental da atividade do professor. E finalmente, aborda-rei a questão da função social do professor como intelectual transforma-dor no interior da escola e da universidade.

\section{A DIMENSÃO REFLEXIVA DA PRÁTICA DO PROFESSOR}

Durante o processo de formação docente uma pergunta se faz fundamental: qual a importância da reflexão sobre a prática ou sobre o conhecimento profissional no momento da formação inicial do futuro professor? Apesar de ser decisiva para a qualidade do trabalho docente, a dimensão reflexiva da prática do professor tem sido desconsiderada em grande parte dos cursos formadores e as conseqüências desta negligência podem ser percebidas através da desvalorização crescente da práxis educativa. As licenciaturas em Educação Física preocupam-se demasia-damente com a formação técnica derivada do conhecimento científico, em detrimento da formação intelectual crítica. As habilidades técnicas do conhecimento não são suficientes para o professor compreender a realidade que o cerca e apreender as diferentes situações que as relações professor-aluno, professor-escola e professor-sociedade lhe impõem.

O conhecimento profissional ou o conhecimento sobre a prática docente tem sido cada vez menos valorizado, provavelmente por causa das distâncias que existem entre teoria e prática, universidade e escola, pensamento e ação. Segundo Schon (1992, p. 80), esta crise de confiança no conhecimento profissional está desencadeando uma busca de uma nova epistemologia da prática profissional: “ Na educação, esta crise centra-se num conflito entre o saber escolar e a reflexão-na-ação dos professores e alunos.”

A influência da concepção de que "na prática a teoria é outra”, que tenta alargar a lacuna entre conhecimento teórico e conhecimento prático, encontra raízes e gera conflitos a partir das “(...) visões de ciência e de profissão presentes na racionalidade técnica derivada do positivismo, com base na qual o conhecimento prático passa a profissional quando se fundamenta em resultados da pesquisa científica” (Moreira,1995, p. 16). Nesta perspectiva, o professor, longe de ser um intelectual autônomo, é considerado um técnicoespecialista que aplica com rigor as regras que derivam do conhecimento científico.

A noção de professor como técnico é fundamentada na concepção 
(...) epistemológica da prática, herdada do positivismo, que prevaleceu ao longo de todo o século XX, servindo de referência para a educação e socialização dos profissionais em geral e dos docentes em particular. (...) Segundo o modelo da racionalidade técnica, a atividade do profissional é sobretudo instrumental, dirigida para a solução de problemas mediante a aplicação rigorosa de teorias e técnicas científicas. (Gómez, 1992, p. 96)

Esta concepção tem influenciado principalmente a maioria dos cursos de formação docente em Educação Física, os quais têm preparado este professor para exercer atividades meramente técnicas, geralmente desconsiderando elementos reflexivos, críticos, sociais e políticos que envolvem todo o processo educativo.

O modelo dominante da racionalidade técnica que envolve grande parte das licenciaturas tem sido responsável pelas grandes dificuldades de conhecimento e de saberfazer necessários aos professores para desempenhar um trabalho eficaz; ao contrário, a hegemonia deste modelo tem contribuído para o fracasso e ineficiência do trabalho docente. "A concepção do ensino como intervenção tecnológica, a investigação baseada no paradigma processo-produto, a concepção do professor como técnico e a formação de professores por competências são indicadores eloqüentes da amplitude temporal e espacial do modelo de racionalidade técnica.” (Gómez, p. 98). Na medida em que se formam professores que apenas cumprem planejamentos do qual não fizeram parte no momento de sua elaboração ou que apenas seguem livros-textos ou livros didáticos, ou ainda pior, professores que seguem apenas sua experiência acumulada na rotina do trabalho escolar, este modelo está longe de formar profissionais reflexivos, capazes de equipar os professores com as capacidades necessárias ao desempenho de seu trabalho e de ir além da rotina imposta pelo sistema escolar.

Segundo Gómez, nas últimas décadas a formação de professores tem sido impregnada por esta concepção linear e simplista dos processos de ensino, abrangendo normalmente dois grandes componentes: um científico-cultural (para assegurar o conhecimento do conteúdo a ensinar) e um psicopedagógico (como atuar eficazmente na sala de aula).

Entretanto, na prática do cotidiano surgem problemas que não podem ser tratados de forma instrumental “(...) em que a tarefa profissional se resume a uma acertada escolha e aplicação de meios e de procedimentos. De um modo geral, na prática não existem problemas, mas sim situações problemáticas, que se apresentam freqüentemente como casos únicos que não se enquadram nas categorias genéricas identificadas pela técnica e pela teoria existentes” (Gómez, p. 100). Isto porque, no decorrer da ação pedagógica, surgem conflitos de natureza diversa que exigem muito mais do professor do que seu conhecimento sobre as técnicas, o que não significa também que se deva abandonar a utilização da racionalidade técnica em qualquer situação da prática educativa. Existem múltiplas tarefas concretas em que a melhor e, por vezes, a única forma de intervenção eficaz consiste na aplicação das teorias e técnicas disponíveis. O que não podemos é considerar a atividade profissional (prática) do professor, como uma atividade exclusivamente técnica. É mais correto encará-la como uma atividade reflexiva e criativa, na qual algumas aplicações concretas de caráter técnico podem ser necessárias.

Exercer a atividade docente, ou seja, "dar aulas" não se resume a uma atividade técnica. $\mathrm{O}$ ato de ensinar não é o mesmo que aplicar métodos e técnicas, ou ainda copiar a receita do bolo na resolução de um problema qualquer que possa surgir nas diversas situações de aula. A dificuldade maior não é encontrar a resposta do problema e sim identificar o problema ou as situações problemáticas. É aqui que se torna necessária a 
capacidade de reflexão e crítica do professor: “ (...) a conversa-reflexiva-com-a-situação permite aos atores repensar a compreensão do que ocorre, refletir sobre suas perspectivas e procurar comunicá-las” (Moreira, 1995, p. 17).

Uma nova concepção da prática profissional que deseja superar a relação linear e mecânica entre a dimensão científico-técnica do conhecimento da Educação Física e a prática na aula pode ser construída a partir dos conceitos de reflexão na ação, teoria de autoria de Donald Schon que vem sendo muito divulgada. Este autor trata da questão da reflexão como um componente complexo e importante da atividade do professor.

O professor continuamente utiliza-se de recursos intelectuais e reflexivos durante as múltiplas solicitações da vida escolar como conceitos, crenças, teorias e técnicas a fim de encontrar respostas para as situações-problemas com que se depara. Sendo assim, mesmo inconscientemente, o professor utiliza-se de processos de reflexão de acordo com suas possibilidades e limites. Daí a importância de se compreender e discutir a natureza do processo de reflexão de maneira que possa contribuir efetivamente no interior dos cursos de formação docente em Educação Física.

A reflexão não é determinada biológica ou psicologicamente, nem é pensamento puro, antes expressa uma orientação para a ação e refere-se às relações entre o pensamento e a ação nas situações históricas em que nos encontramos; não é uma forma individualista de trabalho mental, quer seja mecânica ou especulativa, pois depende das relações sociais; não é independente dos valores, nem neutra, pois expressa e serve interesses humanos, políticos culturais e sociais particulares; não é indiferente nem passiva perante a ordem social, nem propaga meramente valores sociais de consenso, pois reproduz ou transforma ativamente as práticas ideológicas que estão na base da ordem social; não é um processo mecânico, nem simplesmente um exercício criativo de construção de novas idéias, antes é uma prática que exprime o nosso poder para reconstruir a vida social, ao participar na comunicação, na tomada de decisões e na ação social ( Kemmis, apud Gomez, 1992).

Nesta perspectiva, a reflexão é tratada como conhecimento deter-minado pelas experiências da vida, por interesses sociais e políticos, intercâmbios simbólicos, valores e afetividades. Ou seja, não é um conhecimento puro mas contaminado pela vida social.

É preciso distinguir três conceitos diferentes que integram o pensamento prático para compreender melhor a questão da reflexão como componente complexo e importante da atividade do professor: conhecimento-na-ação, reflexão-na-ação e reflexão sobre a ação e sobre a reflexão-na-ação (Schon, 1983).

O conhecimento-na-ação, conhecimento técnico ou solução de problemas, é o componente inteligente que orienta toda a atividade humana e se manifesta no saber fazer. Há um tipo de conhecimento em qualquer ação inteligente, ainda que este conhecimento, fruto da experiência e da reflexão passadas, se tenha consolidado em esquemas automáticos ou em rotinas. Esta dimensão do pensamento profissional tem sido a mais utilizada pelos professores de Educação Física.

A atividade prática implica também e ao mesmo tempo em pensar sobre aquilo que estamos fazendo. Schon chama este componente do pensamento prático reflexão-na-ação ou deliberação prática. Ao conhecimento de primeira ordem sobrepõe-se um conhecimento de segunda ordem, isto é, um processo de diálogo com a situação problemática e sobre uma interação particular que exige uma intervenção concreta. É um processo de reflexão sem o rigor, a sistematização e o distanciamento requeridos pela análise racional, mas com a riqueza da improvisação e da criação. Quando o profissional se revela flexível e aberto às situações problemáticas da prática, a reflexão-na-ação é o melhor instrumento de 
aprendizagem. No contato com a situação prática, não só se adquirem e se constroem novas teorias e conceitos, como se aprende o processo de aprendizagem a partir do diálogo entre a teoria e a prática.

A reflexão sobre a ação e sobre a reflexão-na-ação, ou reflexão crítica, pode considerar-se como a análise que o indivíduo realiza posteriormente sobre as características e os processos da sua própria ação. É a utilização do conhecimento para descrever, analisar e avaliar tudo o que ocorreu, a fim de compreender e reconstruir em novas bases sua prática.

A reflexão sobre a ação supõe, portanto, um conhecimento do conhecimento-na-ação e da reflexão-na-ação. Estes três processos constituem o pensamento prático do professor e são interdependentes entre si, completando-se um ao outro. Por exemplo, quando a prática, com o passar do tempo, se torna repetitiva e rotineira e o conhecimento-na-ação é cada vez mais inconsciente e mecânico, o professor de Educação Física começa a reproduzir automaticamente a sua aparente competência prática e perde importantes oportunidades de aprendizagem pela reflexão na e sobre a ação. Desta forma, o seu conhecimento prático vai-se fossilizando e repetindo, aplicando indiferentemente os mesmos esquemas a situações cada vez menos semelhantes. Fica incapacitado de realizar um diálogo criativo com a complexa situação real. Empobrece-se o seu pensamento e a sua intervenção torna-se rígida. Progressivamente, torna-se insensível às peculiaridades do cotidiano que não se encaixam no seu empobrecido pensamento e pode cometer erros que nem sequer conseguirá detectar.

Nessa perspectiva de reflexão o professor terá condições de se transformar em um investigador na sala de aula na medida em que ele reflete na ação e sobre a ação. “... afastado da racionalidade instrumental, o professor não depende das técnicas, regras e receitas derivadas de uma teoria externa, nem das pressões curriculares impostas do exterior pela administração ou pelo esquema preestabelecido no manual escolar” (Goméz, 1992).

Nesse sentido, a formação de professores de Educação Física deve proporcionar situações que possibilitem a reflexão e a conscientização das limitações sociais, culturais e ideológicas da própria profissão docente.

O conhecimento a respeito do ato de ensinar só é efetivamente apreendido a partir da própria prática, por ser experimental e carregado de valor. O conhecimento prático pessoal adquire-se por tentativas, está sujeito a mudanças, não pode ser entendido como algo fixo e sem alteração. Esse conhecimento prático e pessoal implica uma relação de diálogo entre a teoria e a prática. O pensamento dos professores sobre a prática é algo que realmente influencia e determina a prática de ensino da Educação Física, uma vez que os professores possuem, mesmo inconsciente-mente, teorias implícitas, crenças, ou seja uma compreensão própria sobre a prática pedagógica, daí a importância da ênfase na capacidade reflexiva do professor sobre sua própria ação.

Acredito que o conceito de reflexão deva ser melhor explicitado, discutido e compreendido por todas as pessoas envolvidas com a questão da formação de professores e não apenas citado em discursos e palestras sem o necessário rigor e complexidade que envolvem esta concepção. Percebo que todos concordam com uma formação crítica e reflexiva, incluindo alunos e professores, entretanto esta questão vem sendo pouco debatida no interior das licenciaturas em Educação Física e muitos 
licenciandos e professores, na realidade, estão falando em ensino crítico e reflexivo sem realmente incorporar este discurso à sua prática, talvez porque o tema não tem encontrado o espaço necessário para sua real apreensão.

Se quisermos realmente lutar pela transformação do atual modelo de formação de professores de Educação Física vigente, todas estas questões apontadas devem ser aprofundadas na tentativa de sua superação. Portanto, a luta por um modelo que privilegie a formação crítica e reflexiva não é unilateral, porque possui outras dimensões que também devem ser consideradas, como as concepções de escola, de currículo, de professor, de salas de aula e de licenciatura, as quais devem estar claras nos projetos político-pedagógico de formação de professores de Educação Física.

\section{O PROFESSOR DE EDUCAÇÃO FÍSICA ENQUANTO INTELECTUAL TRANSFORMADOR}

O papel do professor é um aspecto fundamental nesta discussão. O professor não é um técnico e, portanto, não pode estar limitado à execução de planejamentos elaborados por terceiros. Ao contrário, ele exerce o trabalho de intelectual, deve assumir suas responsabilidades pedagógicas e políticas, sua atuação deve ser de intelectual crítico, autônomo e criativo, que se preocupa em tornar o conhecimento de que trata a Educação Física (cultura corporal) mais significativo e emancipador.

Nesta perspectiva, as licenciaturas devem formar professores que tenham condições de desempenhar o papel de intelectual transformador (conceito trabalhado por Moreira). Instrumentalizar o docente nesta direção significa valorizar a função do professor enquanto intelectual. $\mathrm{O}$ intelectual transformador deve ser entendido como aquele cujas atividades se fundamentam em um discurso moral e ético pautado na preocupação com o sofrimento e com as lutas dos oprimidos; com o esforço por tornar o pedagógico mais político (inserindo a educação na esfera política e entendendo a escolarização como luta em torno da definição de significados e de relações de poder) e o político mais pedagógico (tratando seus estudantes como agentes críticos, questionando como o conhecimento é produzido e distribuído, utilizando o diálogo e procurando tornar o conhecimento curricular significativo, crítico e emancipador).

Em uma sociedade como a brasileira, com desenvolvimento acentuadamente desigual, apresentando profundos contrastes, a concepção do professor como intelectual transformador deve ser realmente levada a sério pelas instituições formadoras. Conceber a atividade docente nesta perspectiva implica perceber a "atividade do professor numa sociedade subdesenvolvida, e o caráter político do que ele faz e do que deixa de fazer" (Fernandes, 1986, p. 14). Pensar a realidade politicamente é condição necessária para que o professor possa agir em uma perspectiva transformadora.

Pensar politicamente é alguma coisa que não se aprende fora da prática. Se o professor pensa que sua tarefa é ensinar apenas os funda-mentos do esporte e ignora a pessoa de seus estudantes e as condições em que vivem, obviamente ele não vai aprender a pensar politicamente ou talvez vá agir politicamente em termos conservadores. Vários problemas e temas como o desprestígio crescente do professor como profissional, as relações imperialistas de dominação entre o Brasil e os países centrais, e a degradação do ensino público mostram a necessidade de o professor, no seu cotidiano, ter uma consciência política aguda, firme e exemplar. Não que ele deva se tornar um "salvador da pátria”, mas 
ele precisa ter instrumentos intelectuais para ser crítico diante desta realidade e para desenvolver uma nova prática, que vá além dos muros da escola.

Ciente da situação de um país como o nosso com tantas situações de opressão, os projetos de formação das licenciaturas devem-se preocupar em armar o professor de uma maior consciência política: “O professor precisa se colocar na situação de um cidadão de uma sociedade capitalista subdesenvolvida e com problemas especiais e, nesse quadro, reconhecer que tem um amplo conjunto de potencialidades, que só poderão ser dinamizados se ele agir politicamente, se conjugar uma prática pedagógica eficiente a uma ação política da mesma qualidade” (Fernandes, p. 31). O papel do professor de Educação Física, portanto, não se resume em aplicar as técnicas de ensino ao conteúdo escolar, ele é também um cidadão, que, pelo menos teoricamente, prepara outros cidadãos, humanizando os homens e instrumentalizando-os para exercer sua cidadania.

Moreira (1995) propõe que se acrescente à preocupação com a função social do professor presente na idéia de intelectual transformador a dimensão mais acadêmica do pesquisar-em-ação. Ou seja, o professor como intelectual transformador é ao mesmo tempo um pesquisador de sua prática, a qual assume um sentido reflexivo. Sugere, portanto,

(...) que os/as professores/as universitário/as, orientados/as por uma concepção de prática docente como contexto produtor e não apenas consumidor de conhecimentos, colaborem com os/as futuros/as professores/as em estudos que os/as ajudem a refletir sobre seus processos de ensino e de aprendizagem, estimulando-os a investigar seus desempenhos ou a participar de pesquisas já em andamento. (p. 18).

O autor recomenda também que se desenvolvam ambientes e materiais instrucionais que favoreçam a reflexão do futuro professor, além de alertar para a necessidade que o professor que forma professores tem de também se tornar um intelectual, um pesquisador em ação: "Isso requer a ampliação da idéia de pesquisa, de forma a incluir nesse rótulo a investigação disciplinada e reflexiva sobre a prática. Em outras palavras estou sugerindo que o/a formador/a de professores/as produza conhecimento, fundamentalmente, a partir de engajamento na investiga-ção reflexiva de sua própria prática” (p. 18). A preocupação deste autor nos mostra que qualquer tentativa de mudança no processo de formação docente em Educação Física não será possível se os educadores que educam os educadores não assumirem atitudes de intelectuais responsáveis com toda a questão acadêmica e social na perspectiva de serem eles também intelectuais transformadores e reflexivos.

\section{CONCLUSÃO}

Concluindo, devo afirmar que o tema sobre o qual me propus discorrer não foi aprofundado suficientemente. Mesmo assim, acredito que os estudos sobre uma prática reflexiva podem contribuir muito para o debate na área da Educação Física e seria um grande avanço se as licenciaturas incorporassem em seus projetos político-pedagógicos de formação mecanismos que possibilitassem a construção de uma prática profissional que incorporasse em seu cotidiano os processos reflexivos, de crítica, de análise da realidade e de sua própria ação enquanto intelec-tual comprometido com projetos educacionais de superação e de mudança. 
The main idea of this article is to discuss the Physical Education teachers' formation from a teacher' $\mathrm{s}$ conception as an intelectual - reflective - transformer. First I will try to discuss the current model of the Physical Education teachers' formation and to approach the importance of the pratice as a teacher's instrument of analysis and reflection as an alternative to the dominant paradigm of the technic rationality.

Second, I will discuss the necessity of construction of a new conception of the teacher's pratice which selects the reflective dimension as an essencial component of the teacher's pratice. And finally, I will present the teacher's social function as a transformer intelectual inside the school and the university.

KEY WORDS: Teacher's formation - physical education - education.

\section{REFERÊNCIAS BIBLIOGRÁFICAS}

GARCÍA, Carlos Marcelo. A formação de professores: novas perspectivas baseadas na investigação sobre o pensamento do professor. In: NÓVOA, A. (Coord.). Os professores e a sua formação. Lisboa: Dom Quixote, 1992.

GÓMEZ, Angel Pérez. O pensamento prático do professor - a formação do professor como profissional reflexivo. In: NÓVOA, A. (Coord.) Os professores e a sua formação. Lisboa: Dom Quixote, 1992.

MOREIRA, Antônio Flávio. O currículo como política cultural e a formação docente. In: SILVA, T.T. (Org.) Territórios contestados: o currículo e os novos mapas políticos e culturais. Petrópolis, R.J.: Vozes, 1995.

SCHON, Donald A. Formar professores como profissionais reflexivos. In: NÓVOA, A. (Coord.) Os professores e a sua formação. Lisboa: Dom Quixote, 1992. 